Selcuk Journal of Agriculture and Food Sciences

http://sjafs.selcuk.edu.tr/sjafs/index

Research Article
SJAFS

(2019) 33 (3), 154-162

e-ISSN: 2458-8377

DOI:10.15316/SJAFS.2019.169

\title{
User Awareness for the Benefits of Urban Parks: Ankara City Case*
}

\author{
Sema Melike KILIÇ ${ }^{1, *}$, Ahmet Tuğrul POLAT ${ }^{1}$ \\ ${ }^{1}$ Selcuk University, Faculty of Agriculture, Department of Landscape Architecture, Konya, Turkey
}

\begin{tabular}{l}
\hline ARTICLE INFO \\
\hline Article history: \\
Received date: 08.07 .2019 \\
Accepted date: 22.07 .2019 \\
\hline Edited by: \\
Duran YAVUZ; Selçuk University, \\
Turkey \\
Reviewed by: \\
Metin DEMIR; Atatürk University, \\
Turkey \\
Nurgül ARISOY; Selçuk University, \\
Turkey \\
\hline
\end{tabular}

Keywords:

Urban Parks

Urban Landscape

User Awareness

Park

Park Users

\begin{abstract}
In today's world, people living in the city face difficulties in coping with stress, anxiety and fatigue. The individuals are in the need of being in touch with the nature and relieving stress and pressure in order to get away from these emotions. The parks which are one of the remedial opportunities for the individuals in their living places in terms of spiritual and physical aspects have a positive impact on the life quality of these individuals. In the contemporary societies, the existing open spaces and new designing spaces are regulated in accordance with the requirements of the age and the society given. In this regard, while urban parks, which are one of the important factors of urban landscape, are presented to the user service, it is significant to ensure balance the relationship between environment and human in order to increase the benefits obtained from these parks. The experts and institutions involved in the planning, design and management of such parks possess certain knowledge of these benefits. However, the level of knowledge and awareness of urban population or park users are not clear. In this study, in the case of Ankara city, it was researched how much the park users have knowledge of the economic, ecological, social and physical benefits of urban parks. One-on-one interviews with make a survey were conducted with 384 urban park users. According to the findings, $47.2 \%$ of the participants stated that they do not have general information about the benefits of urban parks, $31.8 \%$ of them that they had knowledge, and $20.8 \%$ said that they are not interested. The participants stated that urban parks were effective in cleaning the polluted air $(37.5 \%)$, lowering the urban temperature $(33.3 \%)$ and increasing the relative air humidity (31.3\%). Based on these findings, suggestions were made to the researches, professional disciplines and public institutions.
\end{abstract}

\section{Introduction}

Urban is a set of relations that reflects all of the established relationships in a society (Harvey, 2013). In today's world, the world is rapidly urbanizing, and by 2030 more than $60 \%$ of the world population is expected to live in cities (Bolund and Hunhammar, 1999). The phenomenon of migration from rural to urban has begun to take place in Turkey especially since 1950s, and the concepts of city and urbanization have emerged. The continuation of migration from rural to city, placing great demands on urban capacities, and the fatigue and pressure of the individuals' struggle to maintain their lives are the common problems of people who live in the cities.

In today's world, people living in the city face difficulties in coping with stress, anxiety and fatigue. The

\footnotetext{
*Corresponding author email: atpolat@selcuk.edu.tr

*This study was produced from Master's thesis of Sema Melike KILIÇ
}

individuals are in the need of being in touch with the nature and relieving stress and pressure in order to get away from these emotions. The parks which are one of the remedial opportunities for the individuals in their living places in terms of spiritual and physical aspects have a positive impact on the life quality of these individuals.

Urban parks are the places which are designed suitable for active and passive recreation areas and for people of all ages with the natural and cultural aspects of the city. In the contemporary societies, the existing open spaces and new designing spaces are regulated in accordance with the requirements of the age and the society given. In this regard, while urban parks, which are one of the important factors of urban landscape, are presented to the user service, it is significant to ensure balance the relationship between environment and human in order to increase the benefits obtained from these parks. The experts and institutions involved in the planning, design and management of such parks possess certain knowledge of these benefits. However, the 
level of knowledge and awareness of urban population or park users is not clear.

It is important for urban people to know the impact of urban parks on strengthening the environment and human relations.

In this study, in the case of Ankara city, it was researched how much the park users have knowledge of the economic, ecological, social and physical benefits of urban parks. One-on-one interviews with make a survey were conducted with 384 urban park users. Based on these findings, suggestions were made to the researches, professional disciplines and public institutions.

It is considered that determining the urban population's awareness about the benefits of urban parks will contribute to the protection of these parks, the increase in value given to the green areas, and the development of the urban identity and the sense of belonging. It will also strengthen the contribution of users to the planning, implementation and management processes of urban parks based on their preferences.

\section{Benefits of Urban Parks}

\subsection{Economic Benefits of Urban Park}

Trees can contribute to energy conservation since they help to reduce the cost of heating and cooling the buildings. As the research made on this shows, 100 million mature trees ( 3 trees per house) in the cities of the United States have saved 2 million dollars in energy expenditure (Dwyer et al., 1992). Trees serve as wind curtain, decreasing wind speed and reducing air infiltration of buildings by up to $50 \%$, which results in annual heating savings up to $25 \%$ (Millwarda and Sabirb, 2011). Temperatures measured in parks also have a strong relationship with plant density. Measurements were made around Bukit Batok Nature Park (36 hectares) and Clementi Woods Park (12 hectares) in Singapore, which have natural reserve. It was observed that $10 \%$ energy was saved and felt up to 400 meters in Bukit Batok Nature Park (Yu et al., 2006).

Property value and people's consumption habit can be influenced by the presence of parks and green areas. According to this, it has been found that the houses close and adjacent to parks and open areas have approximately $8 \%-20 \%$ higher prices than those in other places. Another study has been found that the rental rates of commercial office properties are about $7 \%$ higher in the areas with a high-quality landscape, including trees (Wolf, 2004). It has been verified that the net benefit in increasing the average urban park size in a medium-sized city can be as high as 160 dollars per house (Jenningsa et al., 2016). In the old town centre of Guangzhou, the price of housing decreases by $6.6 \%$ when the distance to the nearest urban park doubles (Jim and Chen, 2009). A small park of 200.000 dollars is able to cover its own cost in 15 years by providing an additional property tax income of 13.000 dollars (Sherer, 2003).
Apart from cultural infrastructure, historical sites, monuments, various activities and entertainment infrastructure, good quality parks also attract tourists (Olbińska, 2018). Riverwalk Park costed 425.000 dollars is one of the most popular attraction centers for the city's 3.5 billion tourism industry (Sherer, 2003).

\subsection{Ecological Benefits of Urban Park}

Urban parks with vegetation contribute significantly to balancing the urban climate, form the lungs of the cities, eliminate environmental pollution by cleaning the air from the particles, adding oxygen to it and removing carbon dioxide from the atmosphere, and host many birds, animals and flowers by providing the wild life corridors for the city. Parks are instrumental in land reclamation by creating vegetation on many vacant and waste lands in the urban areas; they improve the appearances of the lands and increase the ecological values. In this sense, they are considered as a cheap option for recreational costs (Rabare et al., 2009).

In 1994, the trees in New York eliminated $1.821 \mathrm{mt}$ (metric tons) of air pollution, which was estimated as 9.5 million dollars (Nowak, 2002). In an area where tree cover is dense (e.g. adjacent forest areas within parks), $15 \%$ of ozone, $14 \%$ of sulfur dioxide, $13 \%$ of particulate matter, $8 \%$ of nitrogen dioxide and $0.05 \%$ of carbon monoxide can be cleaned from the air by trees (Sherer, 2003). Trees take the carbon in the $\mathrm{CO}_{2}$ gas and store it as cellulose in the wood tissues and release the oxygen back to the atmosphere. A healthy tree can store approximately $6 \mathrm{~kg}$ or 2.6 tons of carbon in an area of $4047 \mathrm{~m}^{2}$ per year (Barış, 2005).

The air flow rubbing on the building surfaces gets hot and loses it speed, resulting in a constant air flow at a certain level of the urban. For this reason, urban parks are the units that regulate this air flow and make it natural. It has been found that the temperature of the green belts in Frankfurt, which do not exceed 50-100m in the cities, makes a difference of $3.5{ }^{0} \mathrm{C}$ compared to the city center. While making these experiments, it was found that a cool air blow from the green areas and that there was a $5 \%$ increase in relative air humidity compared to the city center (Akdoğan, 1970). In the study of Gerey and Deneke (1986), they have proved that tree reduce air temperature by evaporation in summer. In growing environments suitable for sufficient water intake, a single tree can deliver 400 liters of water to the air by transpiration per day. It has been estimated that this corresponds to 5 room air conditioners operating for an average of 20 hours a day (Atay, 1990). It has been found that a green mass of the green areas in urban areas with warm and humid climatic conditions, depending on location, size, density and tree species, decreases summer temperatures by $4-11^{\circ} \mathrm{C}$, increases winter temperatures by $2-4^{\circ} \mathrm{C}$ and creates a balance in receiving solar radiation (Altunkasa, 2004).

\subsection{Social Benefits of Urban Park}

Urban parks play a unique role in establishing the relationship that constitutes social capital. quality parks 
can provide opportunities for volunteering and community events. Parks create community harmony by enabling people to interact with each other in partnerships (Rabare et al., 2009). Urban parks provide a good environment for the interaction of the citizens with each other, an educational area for children and a laboratory environment for studies such as protection of animal species (Sezgin, 1996). By providing spaces and opportunities for physical activity, they play an important role in the increase of satisfaction with their effects on the living environment and health (Konijnendijk et al., 2013). The availability of urban parks that are easily accessible and designed to attract people of all ages can reduce the risk of chronic illness by facilitating physical activity and relieving stress (Sugiyamaa et al., 2018). A study conducted in China examined the role of urban parks in improving physical activity and mental health. Park visits caused a variety of positive mental reactions. According to the results; people expressed to develop themselves in selfconfidence $(69.9 \%)$, energy levels $(61.4 \%)$, feeling healthy $(60 \%)$, mental healing $(52 \%)$ and relaxation $(37.8 \%)$. A positive relationship was found between the physical activities and mental health of park users and their residents (Liu et al., 2017). According to the results of the study conducted by Kuo and Sullivan (2001); being contact with nature reduces mental fatigue, aggression and violence. Access to public parks and recreational facilities is strongly linked to the reduction of offenses, particularly juvenile offenses (Rabare et al., 2009). The "midnight basketball" programs conducted for a year in Kansas City resulted in a $25 \%$ drop in youth arrests in the region. Similarly, in Fort Worth (Texas), crime fell by $28 \%$ in the onekilometer community centers where midnight basketball was recommended (Sherer, 2003).

\subsection{Physical Benefits of Urban Park}

In these contemporary times, in which urbanization is in the vertical direction, people find themselves lost in tall buildings. Designing open areas and parks by creating a balance in terms of the scale of this structure has a positive effect on people (Öztürk, 2004). The harmony and contrasts created by using the size, form, texture and color characteristics of urban open and green areas create an attractive impact on the urban population. They serve the city as an aesthetic entity that brings vitality and liveliness to the urban landscape with its different colors from season to season. (Özk1r, 2007). They provide links between green spaces, cities and the organic system. They eliminate monotony by occupying the space between the geometric structure patterns of the cities. Thus, while eliminating the dryness of the physical structure of the city, on the other hand, they give the building masses of the city a soft appearance and bring all elements together in an organ- ic order. They help to set mass-space. Green spaces in the city provide the necessary security for people by separating vehicle traffic from pedestrian recreation and settlement areas (Boyac1, 2010).

\section{Materials and Methodology}

\subsection{Materials}

In the study, urban parks and park users in Ankara province were taken as materials (Figure 1). While forming the theoretical foundations of the research, graduate theses, scientific researches, books etc. were used. The A4 size questionnaire forms were used to determine the awareness of the users. SPSS 22 software was used in the statistical analyzes to be applied to the findings obtained from Microsoft Office software during the writing phase.

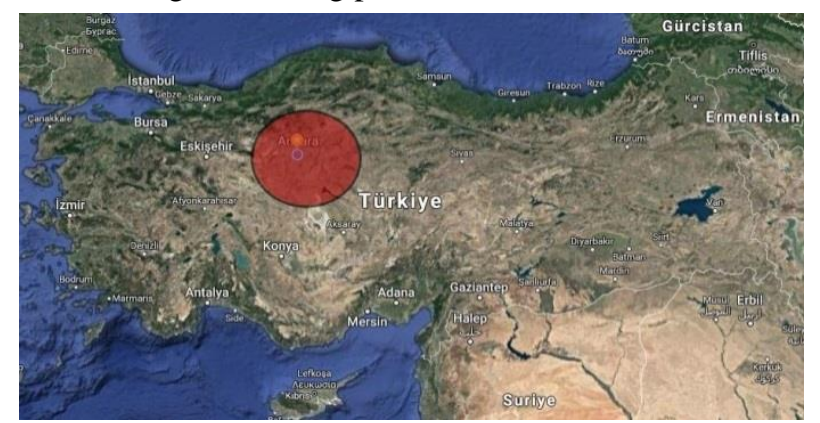

Figure 1

Location of the Research Area (Googleearth, 2019)

\subsection{Methodology}

Research methodology was conducted through the determination of the aim, the literature review, the findings obtained and the formation of the theoretical frameworks in the first stage; through the designing and applying the questionnaire in the second stage; through the organization of the data obtained in the third stage; and the statistical analyses in the last stage.

The economic, ecological, social and physical benefits of urban parks have been demonstrated through the literature review. Based on the theoretical framework, a questionnaire was designed to question the awareness of urban park users about the demographic characteristics and economic, ecological, social and physical benefits of urban parks. Attention was paid to the fact that the questionnaire would be understandable, easy to apply and include purposeful questions. A pre-test was conducted with the designed questionnaire to check for deficiencies and errors. The population of Ankara province was taken as universe size and according to sample size in Table 1, the questionnaire was conducted with 384 participants (Yazıcıoğlu and Erdoğan, 2004). 
Table 1

Samle Sizes for $\alpha=0.05$ (Yazıcıoğlu and Erdoğan, 2004)

\begin{tabular}{lccc}
\hline & \multicolumn{3}{c}{$+\begin{array}{c}\text { Sample Error } \\
\text { Universe size }\end{array}$} \\
\cline { 2 - 4 } & $\begin{array}{c}\mathrm{p}=0.5 \\
\mathrm{q}=0.5\end{array}$ & $\begin{array}{c}\mathrm{p}=0.8 \\
\mathrm{q}=0.2\end{array}$ & $\begin{array}{c}\mathrm{p}=0.3 \\
\mathrm{q}=0.7\end{array}$ \\
\hline 100 & 80 & 71 & 77 \\
\hline 500 & 217 & 165 & 196 \\
\hline 750 & 254 & 185 & 226 \\
\hline 1000 & 278 & 198 & 244 \\
\hline 2500 & 333 & 224 & 286 \\
\hline 5000 & 357 & 234 & 303 \\
\hline 10000 & 370 & 240 & 313 \\
\hline 25000 & 378 & 244 & 319 \\
\hline 50000 & 381 & 245 & 321 \\
\hline 100000 & 383 & 245 & 322 \\
\hline 1000000 & 384 & 246 & 323 \\
\hline 100 milyon & $\mathbf{3 8 4}$ & 245 & 323 \\
\hline
\end{tabular}

The questionnaires were conducted in randomly selected and mutual interviews in Ankara urban parks between 10.00 and 15.00 every day of the week in order to vary in terms of demographic aspects of the subjects.

The data obtained after the survey was transferred to computer and edited with Microsoft Office Excel software. Missing and incorrect questionnaires were excluded from the scope of the research. The frequencies for the findings were determined by using SPSS 22 software.

\section{Results and Discussion}

\subsection{Demographic Characteristics of Participants}

Gender distribution was given in Figure 2 in terms of demographic characteristics of the participants in the survey conducted in the scope of the study. Of the total 384 respondents, $232(60 \%)$ were female and 152 (40\%) were male (Figure 2).

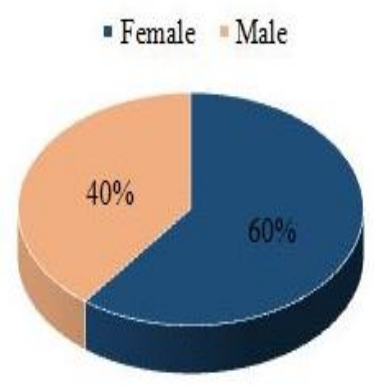

Figure 2

Gender Distributions of Participants

Age distribution was given in Figure 3 in terms of demographic characteristics of the participants in the survey conducted in the scope of the study. According to this, $30 \%$ of the participants were between $18-24$ years old, 35\% were between 25-34 years old, $22 \%$ were between $35-44$ years old, $11 \%$ were between 45 64 years old, $2 \%$ were 65 years and older (Figure 3 ).

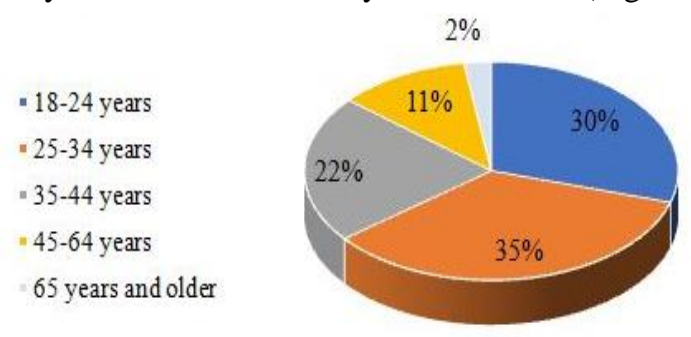

Figure 3

Age Range of Participants

Education status was given in Figure 4 in terms of demographic characteristics of the participants in the survey conducted in the scope of the study. According to this, 1 person is illiterate. $8 \%$ of the survey participants are primary school graduates, $17 \%$ are high school graduates, $9 \%$ are associate degree graduates, $50 \%$ are bachelor degree graduates and $16 \%$ have master's degree graduates (Figure 4).
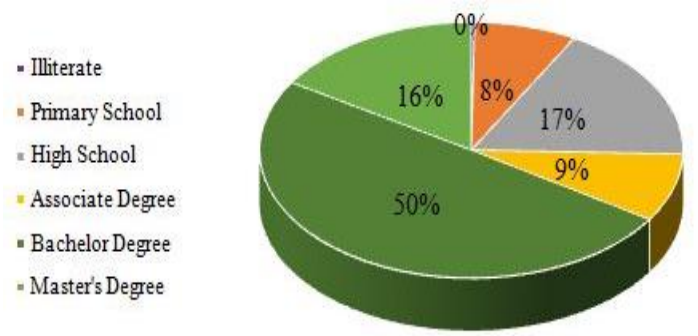

Figure 4

Educational Status of Participants

Occupational groups were given in Figure 5 in terms of demographic characteristics of the participants in the survey conducted in the scope of the study. According to this, $10 \%$ of the survey participants are unemployed, $26 \%$ are workers, $21 \%$ are public employees, $21 \%$ are students, $5 \%$ are housewives, $12 \%$ are self-employed and 5\% are retired (Figure 5).

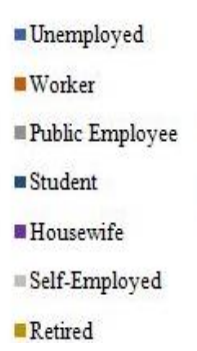

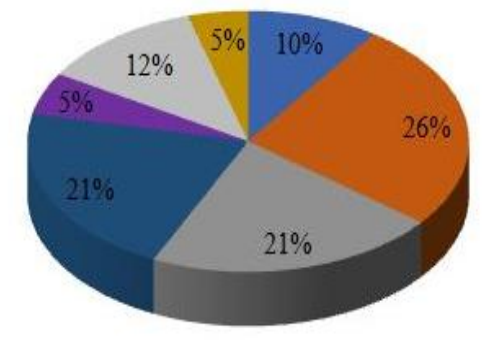

Figure 5

Occupational Groups of Participants

Income groups were given in Figure 6 in terms of demographic characteristics of the participants in the survey conducted in the scope of the study. According to this; $27 \%$ of the survey participants have monthly income of $0-1000 \mathrm{TL}, 23 \%$ of $1000-2000 \mathrm{TL}, 20 \%$ of $2000-3000$ TL, $19 \%$ of $3000-5000$ TL, $11 \%$ of 5000 TL or more (Figure 6). 


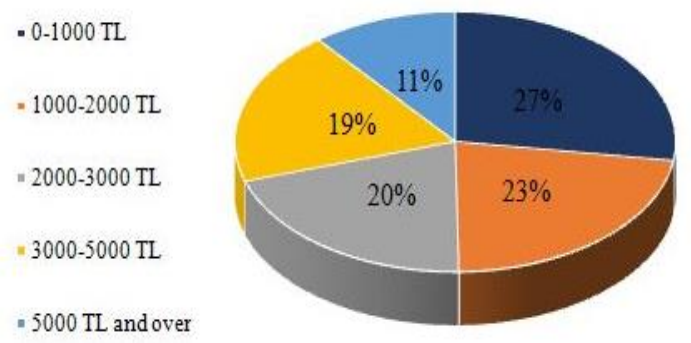

Figure 6

Income Groups of Participants

The condition of living in Ankara was given in Figure 7 in terms of demographic characteristics of the participants in the survey conducted in the scope of the study. According to this, $91 \%$ of the participants live in Ankara and the rest 9\% don't live in Ankara (Figure 7).

\section{- Live in Ankara \\ Don't Live in Ankara}

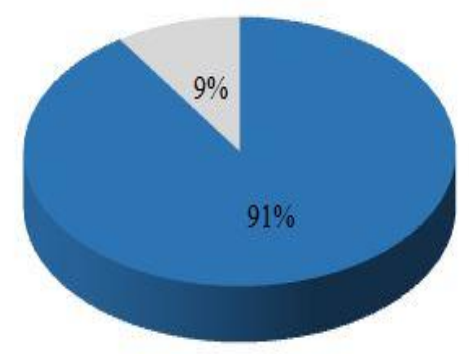

Figure 7

Resident Statuses of Participants

\subsection{Awareness of Participants about Benefits of Urban Parks}

\subsubsection{Overall Awareness of Participants about Bene- fits of Urban Parks}

The knowledge and awareness levels of the park users participating in the survey about the benefits of urban parks were given in Figure 8 in a graphical form. According to this, $12.2 \%$ of the respondents has given the answers do not know, 35.2\% know little, $20.8 \%$ are not interested, $28.4 \%$ have knowledge and $3.4 \%$ have expertise knowledge. According to these rates, $47.2 \%$ of the participants do not have information about the benefits of urban parks, $31.8 \%$ have knowledge of urban parks (Figure 8). It can be said that approximately one-third of urban park users in Ankara are aware of the benefits of green spaces.

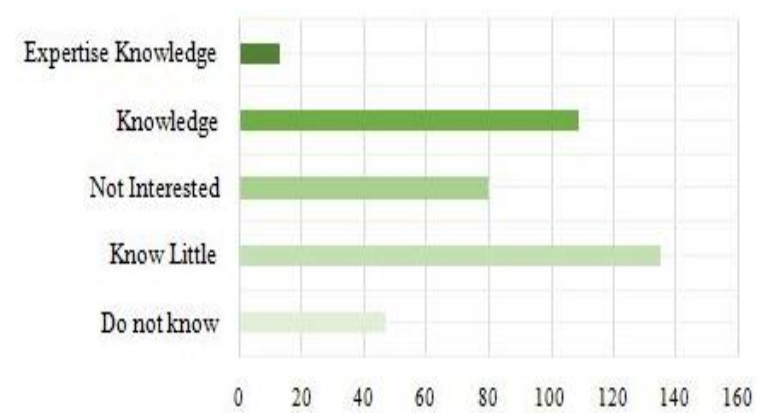

Figure 8

General Awareness of Participants on the Benefits of Urban Parks

4.2.2. Awareness of Participants about Economic Benefits of Urban Parks
The knowledge and awareness of the urban park users participating in the survey about the economic benefits of urban parks (energy saving-urban tourism potential, housing price effect-job opportunity) were given in Figure 9. Regarding the question "Can urban parks provide energy saving for the houses in a certain impact area by cooling the environment in summer and shielding the wind in winter with the plant materials they contain?" $24.2 \%$ the respondents do not have any information about it, $4.7 \%$ stated that urban parks do not definitely provide such benefits, $14.1 \%$ stated that they do not provide such benefits, $47.7 \%$ stated that they provide such benefits, $9.4 \%$ stated that they definitely provide such benefits. $47.7 \%$ of the survey participants are aware that green spaces save energy. According to the findings, one out of four participants do not know about the contribution of plants to energy saving. Regarding the question "Can urban parks provide benefits for the tourism potential of the cities in which they are located?" $6.3 \%$ the respondents do not have any information about it, $7.8 \%$ stated that urban parks do not definitely provide such benefits, $14.6 \%$ stated that they do not provide such benefits, $57.8 \%$ stated that they provide such benefits, $13.5 \%$ stated that they definitely provide such benefits (Figure 9). Ankara is open to foreign tourists since it is the capital city of Turkey. The existence of the post-republic parks in the city and their use in the parks has become the focus of tourists. In additionally, the enterprises and organizations in these parks constitute employment.

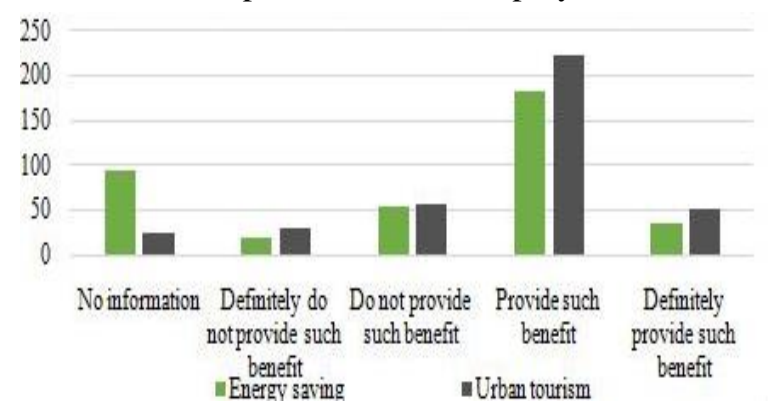

Figure 9

Awareness of Participants about Energy-Saving and Urban Tourism

"Regarding the question "To what extent can a well-designed urban park create impact in the housing prices in its impact zone? Would the price be higher?" $10.7 \%$ do not information about it, $2.9 \%$ stated that there would be no definitely rise at all, $4.9 \%$ stated that there would be no rise, $47.4 \%$ stated that there would be rise, $34.1 \%$ stated that there would be definitely rise. Urban parks increase the welfare level of the environment in which they are located and make them a point of attraction with its structure that brings people together with nature. In parallel with these results, the direct proportional increase in housing prices in Dikmen Valley and its surrounding areas in Ankara in the 2000 s can be given as an example. Regarding the question "Can the organizations held in urban parks (e.g. concerts, festivals, competitions, shows and so on) increase job opportunities for the urban population?" 
$12 \%$ do not have information about it, $4.9 \%$ stated that there would be no definitely rise at all, $14.3 \%$ stated that there would be no rise, $57 \%$ stated that there would be rise, $11.7 \%$ stated that there would be definitely rise (Figure 10). Through the youth organizations and the openings of various festivals held in the urban parks in Ankara, it ensured to appeal to wide masses and to offer job opportunities for the local people. Through the paid-free concerts held in Ulus Genclik Park in Ankara, the rates of socialization are on the rise among the public as there is an increase in job opportunities. Ankapark which is one of the new parks in Ankara hosts various artists and creates job opportunities for people as well.

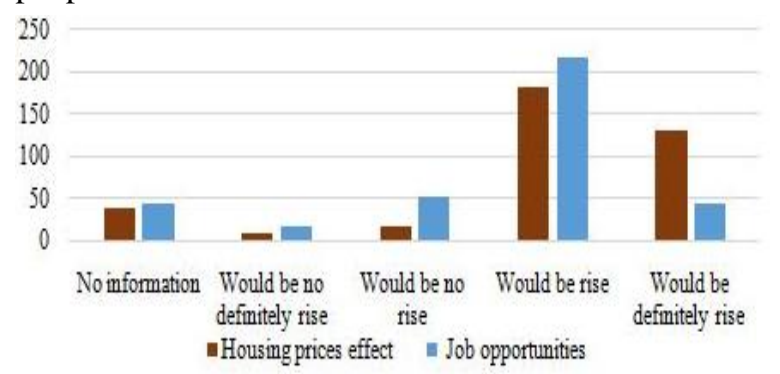

Figure 10

Awareness of Participants about on Housing Prices Effect and Job Opportunities

\subsubsection{Awareness of Participants about Ecological Benefits of Urban Parks}

The knowledge and awareness of the urban park users about the ecological benefits of the urban parks (oxygen production-plant species diversity protection and increase, polluted air cleaning-city temperature reduction-relative air humidity increase, greenhouse effect-noise) were given in Figure 11.

Regarding the question "How useful can urban parks are in the production of oxygen?" $6.5 \%$ of the participants do not have information about it, $8.1 \%$ stated that they are useless, $19.8 \%$ states that they are little useful, $48.4 \%$ stated that they are useful, and $17.2 \%$ stated that they can be very useful. The users of urban parks in Ankara are also aware of the contribution of green spaces to the oxygen cycle for our world and our city. Regarding the question "How useful can urban parks are in the protection and increase of plant species diversity?" $11.7 \%$ of the participants do not have information about it, $12.8 \%$ stated that they are useless, $23.7 \%$ stated that they are little useful, 39.8\% stated they are useful, and $12 \%$ stated that they are very useful (Figure 11). The presence of different plant species in our environment reflects the ecosystem wealth. It enables the design of a healthy green area with the choices of the plants used in the urban parks and the texture and soil of the urban. However, it is required to ensure the landscape design in these parks with the regional plants in order to maintain this diversity in the city. The fact that trees such as oriental plane, birch, cercis and lime trees, which adapt to the climatic conditions in Ankara and reflect Ankara, confirms the findings.

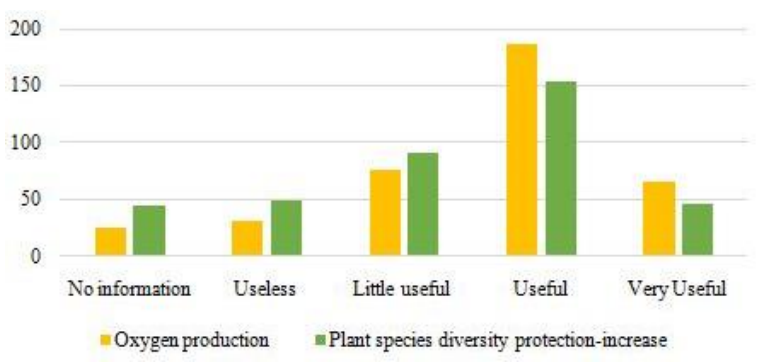

Figure 11

Awareness of Participants about Oxygen-production and Plant Species Diversity Protection and Increase

Regarding the question "How effective can urban parks are in cleaning the polluted air in the city?" $9.1 \%$ of the participants do not have information about it. $10.4 \%$ stated that they are no effect, $26.8 \%$ stated that they are little effective, $37.5 \%$ states that they are effective, $16.1 \%$ stated that they are very effective answered. Through the increasing use of vehicles and different heating methods in Ankara, the weather of the city is negatively affected. However, the presence of green areas in the city and the increase in these green areas produce a reducing effect on its gray appearance. Regarding the question "How effective can urban parks are in reducing the city's temperature in summer?" $14.6 \%$ of the participants do not have information about it. $12.2 \%$ stated that they are no effect, $28.6 \%$ stated that they are little effective, $33.3 \%$ stated that they are effective, $11.2 \%$ stated that they are very effective answered. The presence of green spaces in the city can reduce the temperature of the city. Regarding the question "How effective are city parks in increasing the relative air humidity in summer?" $23.2 \%$ of the participants do not have information about it. $10.7 \%$ stated that they are no effect, $27.6 \%$ stated that they are little effective, $31.3 \%$ stated that they are effective, $7.3 \%$ stated that they are very effective answered (Figure 12).

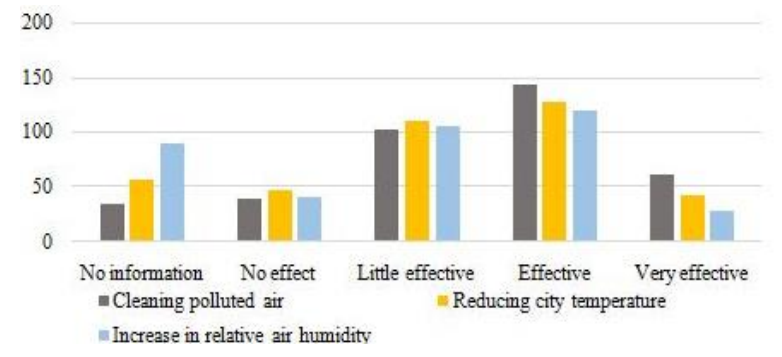

Figure 12

Awareness of the Participants about Cleaning Polluted Air, Reducing City Temperature and Increase Relative Air Humidity

Regarding the question "How much can urban parks reduce the greenhouse effect by holding carbon in the atmosphere?" $25.3 \%$ of the participants do not have information about it. $12 \%$ stated that they cannot reduce it, $32 \%$ stated that they can a little reduce it, $25 \%$ stated that they can reduce it, $5.7 \%$ stated that they can a lot reduce answered. While using the carbon dioxide in the atmosphere for photosynthesis, plants produce oxygen. However, by reducing the amount of 
carbon dioxide in the atmosphere, our world becomes less warm. Regarding the question "To what extent can urban parks reduce environmental noise?" $10.4 \%$ of the participants do not have information about it. $27.9 \%$ stated they cannot reduce it, $21.6 \%$ stated that they can a little reduce it, $29.4 \%$ stated that they can reduce it, $\% 10.7$ of stated that they can a lot reduce answered (Figure 13). Environmental noise can be reduced by the texture and location of the plants. Noise can be prevented by coarse-textured trees or rough-and-denselytextured small trees or shrubs used around the park.

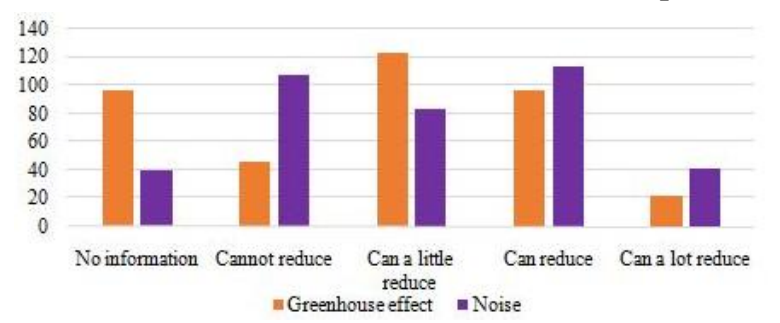

Figure 13

Awareness of Participants about Greenhouse Effect and Noise

\subsubsection{Awareness of Participants about Social Benefits of Urban Parks}

The knowledge and awareness of the urban park users about the social benefits of urban parks (social development-reducing crime rates, public health protection and recreation) were given in Figure 14 in a graphical form. Regarding the question "To what extent can urban parks contribute to social development?" $9.6 \%$ participants do not have information about it. $6 \%$ stated that they do not definitely contribute to it at all, $12.8 \%$ stated they do not contribute to it, $55.2 \%$ stated that they do contribute to it, $16.4 \%$ stated that they do definitely contribute to it. Due to its function as a gathering place, parks bring people from many different cultures together. They bring tourists and the local people together. The socialization rate among people increases with the organizations and daily use of the parks in Ankara. Regarding the question "To what extent can urban parks contribute to reducing crime rates in the city?" $16.1 \%$ of the participants do not have information about it. $2.9 \%$ stated that they do not definitely contribute to it at all, $31 \%$ stated that they do not contribute to it, $24 \%$ stated that they do contribute to it, $6 \%$ stated that they do definitely contribute to it. The users of urban parks in Ankara do not possess awareness about the aspect of urban parks in reducing crime rates. Nevertheless, the well-designed green areas of the urban parks have a healing effect by guiding the urban population. With the revision of the Gençlik Park in 2005 and re-opening in 2009, it constitutes the most populous area of the region and Ankara today. Regarding the question "To what extent can urban parks contribute to protection of public health in the city?" $16.4 \%$ of the participants do not have information about it. $7.6 \%$ stated that they do not definitely contribute to it at all, $19.8 \%$ stated that they do not contribute to it, $44.5 \%$ stated that they do contribute to it,
$11.7 \%$ stated that they do definitely contribute to it (Figure 14). 44,5\% of the urban park users in Ankara are aware of the fact that green areas are useful for the protection of public health. Those who feel good in terms of mental and physical health can become useful individuals for society.

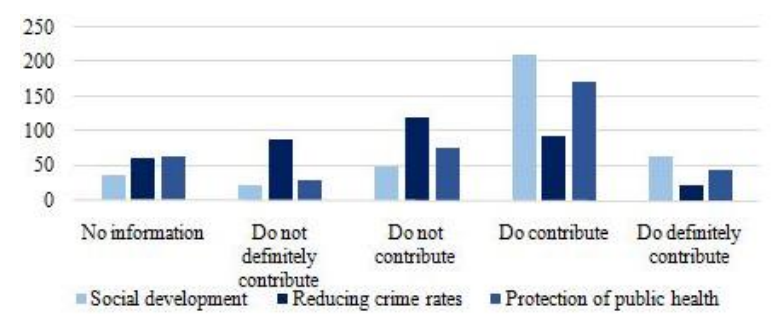

Figure 14

Awareness of Participants about Social Development, Reducing Crime Rates and Protection of Public Health

Regarding the question "How effective are city parks in terms of recreation?" $4.9 \%$ of the participants do not have information about it. $3.6 \%$ stated that they wouldn't be definitely effective at all, $8.3 \%$ stated that they wouldn't effective, $56.5 \%$ stated that they would be effective, $26.6 \%$ stated that they would be definitely effective (Figure 15). The urban park users in Ankara go to the parks in order to gain energy and spend their weekends. The choices of the individuals about spending their leisure time can be varied according to their needs and interests. The urban parks offer different recreational alternatives for people such as horseback riding in Altınpark and fishing in Göksu Park.

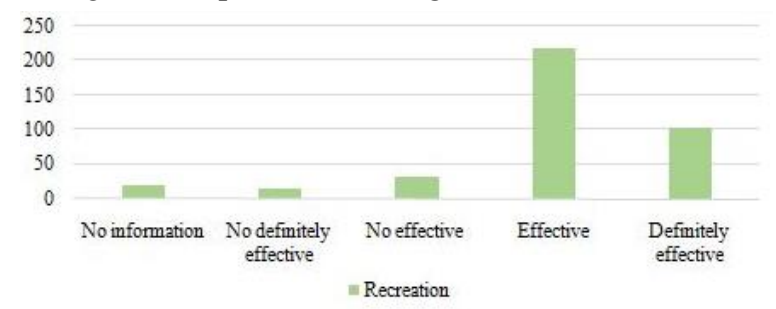

Figure 15

Awareness of Participants about Recreation

\subsubsection{Awareness of Participants about Physical Bene- fits of Urban Parks}

The knowledge and awareness of the participants about the physical benefits of urban parks (visual impact-buffer zone, impact of tall buildings on people, protection of historical building and places) were given in Figure 16. Regarding the question "To what extent can urban parks contribute to the visual attraction of the city?" $2.9 \%$ of the participants do not have information about it. $4.9 \%$ stated that they do not definitely contribute to it at all, $5.7 \%$ stated that they do not contribute to it, $50.5 \%$ stated that they do contribute to it, $5.9 \%$ stated that they do definitely contribute to it a lot. "Regarding the question "Can urban parks contribute to the city by providing a buffer zone among the different areas such as accommodation, trade, business and education?" $22.4 \%$ of the participants do not have information about it. $5.5 \%$ stated that they do not definitely 
contribute to it at all, $11.2 \%$ stated that they do not contribute to it, $47.1 \%$ stated that they do contribute to it, $13.8 \%$ stated that they do definitely contribute to it a lot (Figure 16). A well-designed urban park contributes to the aesthetics of the urban positively. Additionally, the location of green areas in the urban is as important as their beauty. If green areas are used as a boundary, or a limitation to certain places in the city, the aesthetic and location integrity will be achieved. In this way, the planning development of the urban will be possible to be guided.

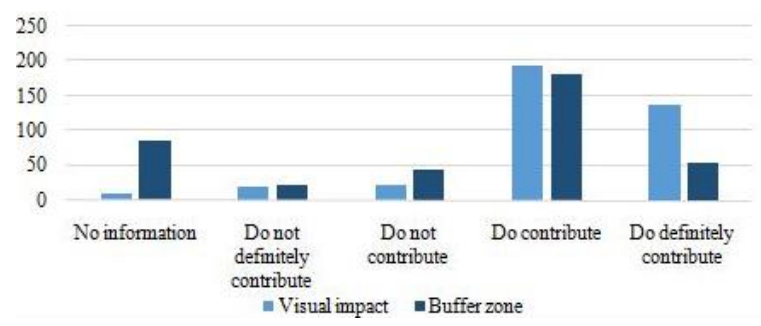

Figure 16

Awareness of Participants about Visual Attraction and Buffer Zone

Regarding the question "To what extent can urban parks useful for reducing the effect of tall buildings on people?" $7.8 \%$ of the participants do not have information about it. $4.7 \%$ stated that they cannot definitely useful for it at all, $8.3 \%$ stated that they cannot useful for it, $45.4 \%$ stated that they can useful for it, $34.1 \%$ stated that they can definitely useful for it (Figure 17). Through the vertical development in recent years, people feel themselves as small dots. In the urban parks where the horizontal development has been ensured, the comfort rates can be boosted. There are physical and mental differences between the individual among tall buildings and the one in an urban park in Ankara. Additionally, $45.4 \%$ of the urban park users in Ankara are aware of the fact that urban parks create a positive effect on reducing the pressure of tall buildings on people.

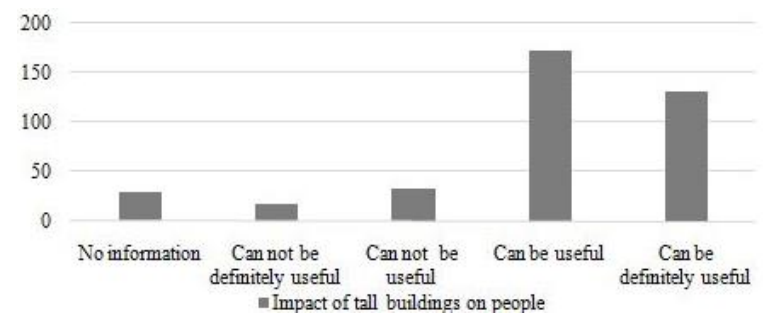

Figure 17

Awareness of Participants about Reducing oppression of Tall Buildings on People

Regarding the question "How effective are city parks protection of historical buildings and places?" $22.1 \%$ of the participants do not have information about it. $9.1 \%$ stated that they wouldn't be definitely effective at all, $25.5 \%$ stated that they wouldn't effective, $34.4 \%$ stated that they would be effective, $8.9 \%$ stated that they would be definitely effective (Figure 18). Societies should pay special attention to historical places. Ensuring the protection and availability of these places can raise public awareness accordingly.

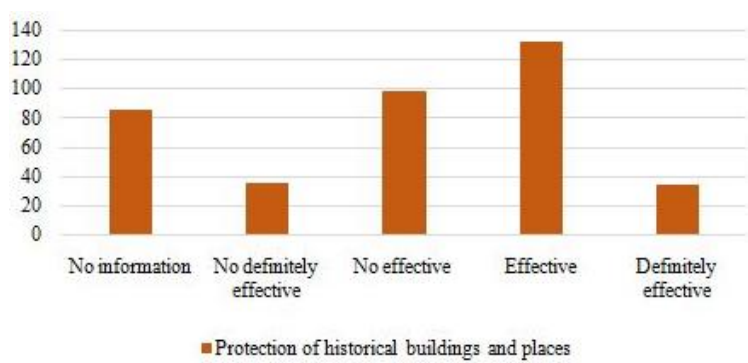

Figure 18

Awareness of Participants about Protection of Historical Buildings and Places

\section{Results and Recommendations}

While urban parks provide space for the city and the inhabitants to breathe, they can guide the socioeconomic situation and development of the city. Urban parks are more than a park. The green areas are comfort zones for the urbanite with its size, variety and accessibility. Parks have economic, ecological, social and physical benefits. Ankara is an important city politically and physically since it is the capital city of Turkey. For its planned infrastructure and the innovative and environment-friendly approaches Ankara can be created a different capital atmosphere in accordance with the urbanite.

In Ankara, urban parks are designed and implemented by local governments and offered to the service of the city people. As a result of the usage of these parks by the people of the urban, some user-based evaluations and interpretations emerge. In recent years, satisfaction surveys have been conducted for the use of parks. When viewed from this angle, the question "To what extent does the level of knowledge of urban park users reflect their satisfaction with this service?" is raised. The location of the green areas and urban parks in the city should be planned according to the needs. The $35.2 \%$ of the urban park users in Ankara answered that they know a little when the question about their knowledge and awareness levels is asked. The urban park users in Ankara stated that they do not possess enough awareness about the overall benefits of urban parks.

According to the results of the research, the knowledge and awareness of the users about the benefits of the parks are generally low. Interestingly enough, their levels of knowledge and awareness about the economic, ecological, social and physical benefits have emerged at higher levels. Besides, regarding the question "How much can urban parks reduce the greenhouse effect by holding carbon in the atmosphere?" $32 \%$ of the participants stated that they can reduce it a little and regarding the question "To what extent can urban parks contribute to reducing crime rates in the city?" $31 \%$ of the participants stated that they do not contribute to it.

Today we need social green spaces such as urban parks in order to strengthen our changing social ties 
with developing technology. With the increasing population in Ankara, the amount of green areas per capita should be increased in line with the needs of the citizens and due to the benefits of urban parks.

Urban parks should be located in city center for easy access of people in the city. Through a simple design, urban parks should be places in which the public can feel and live. Through the coordination between landscape architecture and other disciplines, the local authorities should produce solution alternatives regarding the designing, planning, implementation and sustainability stages of urban parks. It is inevitable to form new green areas for the increasing population in Ankara. People in Ankara should be asked about their preferences for the existing urban parks, the deficiencies of these parks and their expectations from new parks. In this way, the qualities of urban parks can be enhanced.

The urban park users who possess knowledge and awareness can take active roles in changing the services of the local authorities. In this sense, the awareness-raising and information activities about the benefits of urban parks should be conducted for people in Ankara in order to ensure sensitivity about the city planning, the use and sustainability of natural sources and the environmental problems. Additionally, the local authorities should be informed about these issues, and it should be ensured that the local authorities include the conscious park users as stakeholders in the activities about the planning and implementation of parks.

\section{References}

Akdoğan G (1970). Climatic Effects of Green Areas and Their Functions in City Planning, Journal of Landscape Architecture 1: 7-11. (in Turkish)

Altunkasa F (2004). Urban Development Process of Adana and Green Areas (pp. 23), Adana. (in Turkish)

Atay İ (1990). Urban Forests and Interactions with the Environment, Journal of Istanbul University Faculty of Forestry 40: 2-5. (in Turkish)

Barış ME (2005). Urban Planning, Urban Ecosystem and Trees, Union of Chambers of Turkish Engineers and Architects (TMMOB) Chamber of City Planners Publication 4: 156-163. (in Turkish)

Bolund P, Hunhammar S (1999). Ecosystem Services in Urban Areas, Ecological Economics 29: 293-301.

Boyac1 E (2010). Factors Determining City Park Functions In Our Country. Master Thesis, Ankara University Institute of Science and Technology (Unpublished), Ankara. (in Turkish)

Dwyer J, Mcpherson EG, Schroeder HW, Rowntree RA (1992). Assessing the Benefits and Costs of the Urban Forest, Journal of Arboriculture, 18: 227-234.

Googleearth (2019). [Access Date 18.02.2019]
Harvey D (2013). Social Justice and the City, Metis Publications, İstanbul. (in Turkish)

Jenningsa TE, Jean-Philippea SR, Willcoxa A, Zobel JM, Poudyala NC, Simpson T (2016). The Influence of Attitudes and Perception of Tree Benefits on Park Management Priorities. Landscape and Urban Planning 153: $122-128$.

Jim CY, Chen WY (2009). Ecosystem services and valuation of urban forests in China, Cities, 26: 187-194.

Konijnendijk CC, Annerstedt M, Nielsen AB, Maruthaveeran $S$ (2013). Benefits of Urban Parks, https://worldurbanparks.org/images/Newsletters/IfpraBen efitsOfUrbanParks.pdf. (Erişim Tarihi: 02.05.2019)

Kuo FE, Sullivan WC (2001). Aggression and Violence in The Inner City, Effects of Environment via Mental Fatigue, Environment and Behavior 33: 543-571.

Liu H, Feng L, Juanyong L, Zhang Y (2017). The Relationships Between Urban Parks, Residents' Physical Activity and Mental Health Benefits: A Case Study from Beijing, China, Journal of Environmental Management 190: 223 230.

Millwarda AA, Sabirb S (2011). Benefits of a forested urban park: What is the value of Allan Gardens to the city of Toronto, Canada? Landscape and Urban Planning 100: $177-188$

Nowak DJ, Satoshi H, Allison B, Greenfield E (2014). Tree and Forest Effects on Air Quality and Human Health in the United States, Environmental Pollution 193: 119-129.

Olbińska K (2018). The Value of Urban Parks in Lodz, Real Estate Management and Valuation 26: 73-88.

Özkır A (2007). Developing A Management Model For Urban Parks. Doktoral Thesis, Ankara University Institute of Science (Unpublished), Ankara. (in Turkish)

Öztürk B (2004). Constituting Urban Open And Green Area System: Model of Kayseri Urban Complex. Doktoral Thesis, Ankara University Institute of Science (Unpublished), Ankara. (in Turkish)

Rabare RS, Okech R, Onyango G M (2009). The Role of Urban Parks and Socio-Economic Development: Case Study of Kisumu Kenya, Theoretical and Empirical Researches in Urban Management 3: 22-36.

Sherer PM (2003). The Benefits of Parks: Why America Needs More City Parks and Open Space, The Trust for Public Land, 1-24.

Sugiyamaa T, Carvera A, Koohsarib MJ, Veitchd J (2018). Advantages of Public Green Spaces in Enhancing Population Health, Landscape and Urban Planning 178: 1217.

Wolf KL (2004). Public Value of Nature: Economics of Urban Trees, Parks and Open Space, Proceedings of the 35th Annual Conference of the Environmental Design Research Association, 2004, Edmond, Okla, pp. 88-92.

Yazıcıoğlu Y, Erdoğan S (2004). Statistical Package for the Social Sciences (SPSS) Applied Scientific Research Methods, Detay Publications, Ankara. (in Turkish)

Yu C, Hien WN (2006). Thermal Benefits of City Parks, Energy and Building 38: 105-120. 